\title{
Transluminal antegrade biopsy using a novel forceps biopsy device for hepaticojejunostomy stricture
}

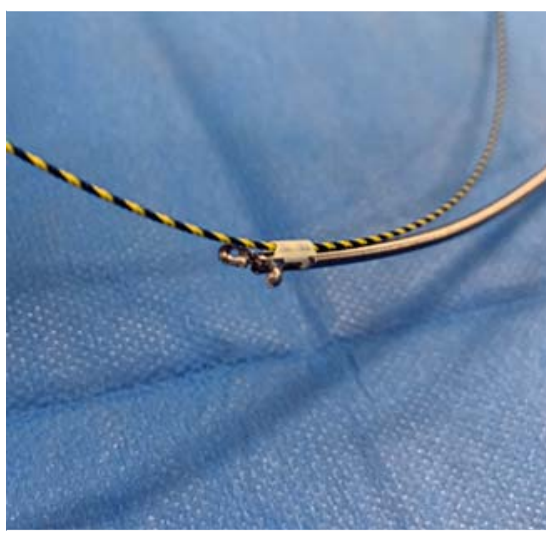

- Fig. 1 The novel forceps biopsy device (Histoguide, STERIS Endoscopy).

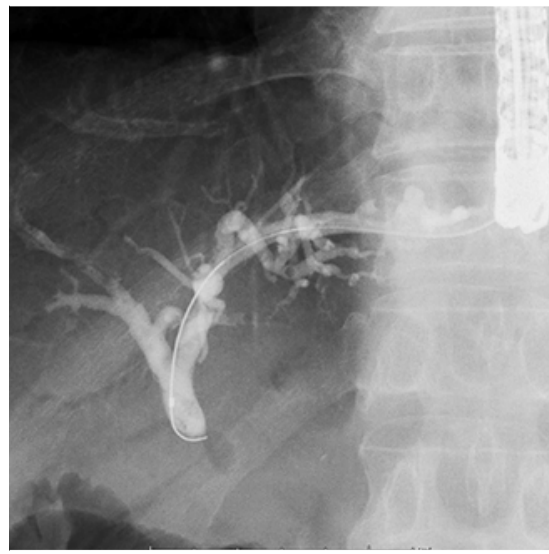

- Fig. 2 Cholangiography revealed biliary obstruction at the hepaticojejunostomy site.

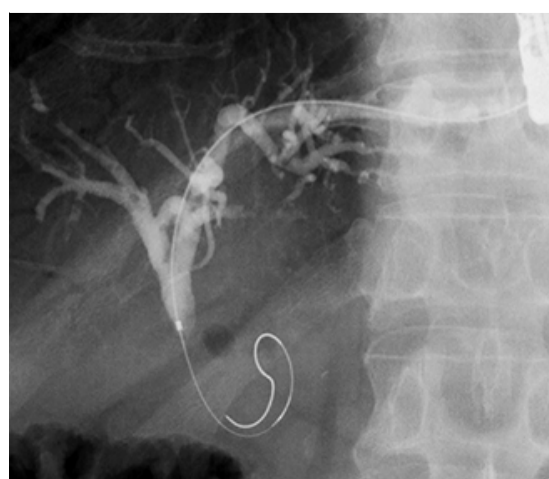

> Fig. 3 The 0.025 -inch guidewire was successfully inserted into the intestine across the stricture site.
The incidence of hepaticojejunostomy strictures may increase in the future with the expansion of the operative indications. Differentiating between a hepaticojejunostomy stricture and a recurrence of primary disease, such as bile duct cancer, is clinically important. A hepaticojejunostomy stricture is usually treated using an endoscopic approach, although technical success is not always achieved with this technique [1]. Hence, endoscopic ultrasound-guided biliary drainage (EUS-BD) has been developed as an alternative method [2-4]. However, obtaining histological evidence of a hepaticojejunostomy stricture is sometimes difficult because transluminal insertion of the biopsy forceps is sometimes challenging due to the acute angle between the left hepatic bile duct and the B3 liver segment. Recently, a forceps biopsy device that can be inserted over the guidewire became available in Japan (Histoguide; STERIS Endoscopy, Mentor, Ohio, USA) (\Fig. 1). We herein describe a successful diagnosis made by obtaining histological tissue of a hepaticojejunostomy stricture through EUS-guided hepaticogastrostomy (EUS-HPG) using the novel forceps biopsy device.

A 60-year-old man was admitted to our hospital owing to frequent cholangitis secondary to a hepaticojejunostomy stricture. EUS-HPG was first attempted using a fully covered self-expandable metal stent. After a fistula was created between the hepatic parenchyma and stomach wall, the stent was removed. Next, the endoscopic retrograde cholangiopancreatography (ERCP) catheter was inserted into the biliary tract through the EUS-HPG route, and contrast medium was injected. Cholangiography demonstrated biliary obstruction at the hepaticojejunostomy site (> Fig.2). Following insertion of an ERCP catheter, a 0.025inch guidewire was inserted into the intestine across the stricture site ( $\triangleright$ Fig. 3 ). Next, the forceps biopsy device was trans-

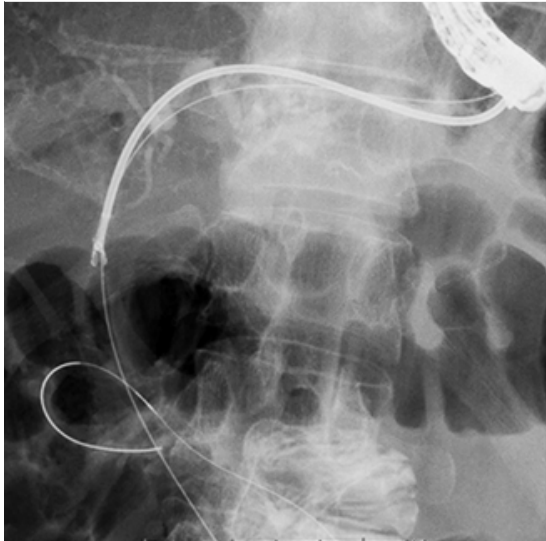

Fig. 4 Antegrade forceps biopsy was successfully performed.

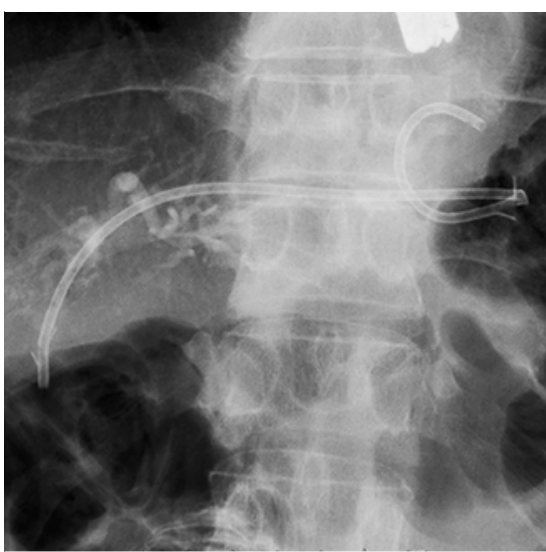

- Fig. 5 Plastic stent deployment was performed from the intrahepatic bile duct to the stomach.

luminally inserted over the guidewire, and an antegrade biopsy was successfully and uneventfully performed (\$Fig.4). Finally, a plastic stent was deployed from the intrahepatic bile duct to the stomach (\Fig.5) (> Video 1). Histopathological evaluation of the biopsy specimen indicated a benign biliary stricture. Our case highlights the clinical feasibility of a transluminal biopsy of a hepaticojejunostomy stricture using the novel forceps biopsy device.

Endoscopy_UCTN_Code_TTT_1AR_2AK 


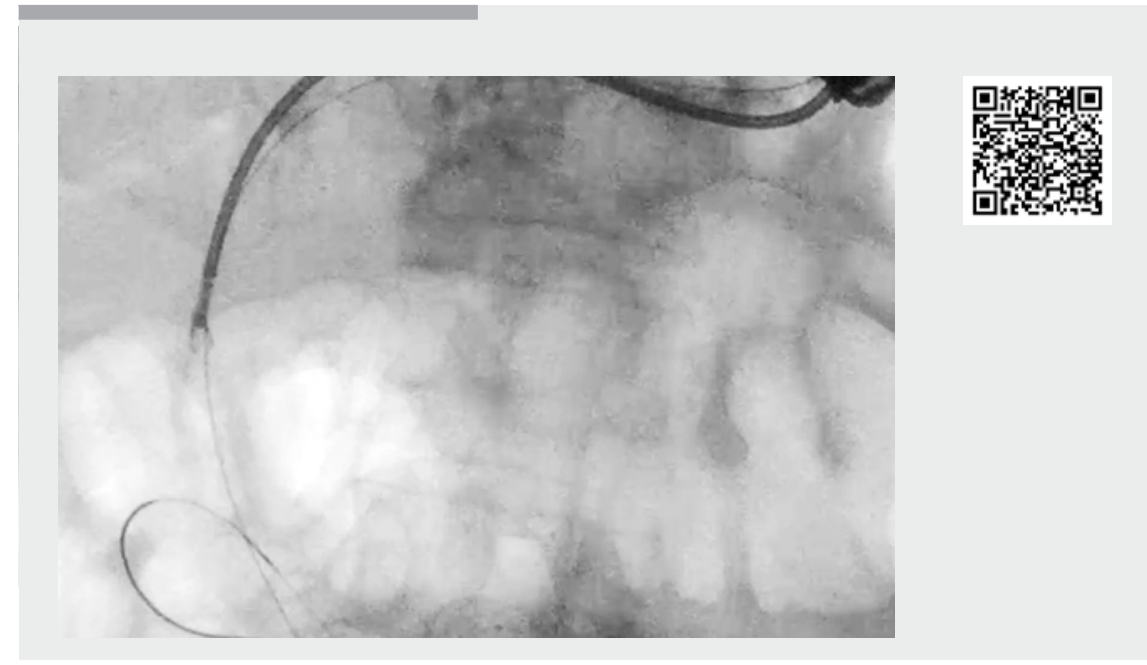

Video 1 Transluminal antegrade biopsy successfully performed using a novel forceps biopsy device for a hepaticojejunostomy stricture.

\section{Competing interests}

The authors declare that they have no conflict of interest.

The authors

Takeshi Ogura, Atsushi Okuda, Nobu Nishioka, Masanori Yamada, Kazuhide Higuchi

2nd Department of Internal Medicine, Osaka Medical College, Osaka, Japan

\section{Corresponding author}

\section{Takeshi Ogura, MD}

2nd Department of Internal Medicine, Osaka Medical College , 2-7 Daigakuchou,

Takatsukishi, Osaka 569-8686, Japan Fax: +81-726846532

oguratakeshi0411@yahoo.co.jp

\section{Bibliography}

Endoscopy 2021; 53: E269-E270

DOI 10.1055/a-1260-2982

ISSN 0013-726X

published online 1.10 .2020

(c) 2020. Thieme. All rights reserved.

Georg Thieme Verlag KG, Rüdigerstraße 14,

70469 Stuttgart, Germany

\section{ENDOSCOPY E-VIDEOS \\ https://eref.thieme.de/e-videos}

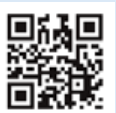

Endoscopy E-Videos is a free access online section, reporting on interesting cases and new techniques in gastroenterological endoscopy. All papers include a high quality video and all contributions are freely accessible online.

This section has its own submission website at https://mc.manuscriptcentral.com/e-videos
[1] Shao XD, Qi XS, Guo XZ. Endoscopic retrograde cholangiopancreatography with double balloon enteroscope in patients with altered gastrointestinal anatomy: a metaanalysis. Saudi J Gastroenterol 2017; 23: 150-160

[2] Nakai $\mathrm{Y}$, Kogure H, Isayama $\mathrm{H}$ et al. Endoscopic ultrasound-guided biliary drainage for benign biliary disease. Clin Endosc 2019; 52: 212-219

[3] Mukai S, Itoi T, Sofuni A et al. EUS-guided antegrade intervention for benign diseases in patients with surgically altered anatomy (with videos). Gastrointest Endosc 2019; 89: 399-407

[4] Ogura T, Nishioka N, Yamada M et al. Novel transluminal treatment protocol for hepaticojejunostomy stricture using covered selfexpandable metal stent. Surg Endosc 2020. doi:10.1007/s00464-020-07381-2 